\title{
Decreased mRNA Expression of Netrin-GI and Netrin-G2 in the Temporal Lobe in Schizophrenia and Bipolar Disorder
}

\author{
Sharon L Eastwood*,' and Paul J Harrison' \\ 'Department of Psychiatry, Warneford Hospital, University of Oxford, Oxford, UK
}

\begin{abstract}
The membrane-bound axon guidance molecules netrin-GI (NTNGI) and netrin-G2 (NTNG2) play a role in synaptic formation and maintenance. Non-coding single nucleotide polymorphisms (SNPs) in both genes have been reported to be associated with schizophrenia. The main aim of this study was to determine if NTNGI and NTNG2 mRNA expression is altered in schizophrenia or bipolar disorder, and/or influenced by disease-associated SNPs. NTNGI and NTNG2 mRNAs were examined in the medial and inferior temporal lobe using in situ hybridization and RT-PCR in the Stanley Medical Research Institute array collection, and in rat hippocampus during development and after antipsychotic administration. NTNGI mRNA isoforms were also examined during human brain development. For NTNG I, the GIc isoform was reduced in bipolar disorder and with a similar trend in schizophrenia; expression of four other NTNGI isoforms was unchanged. In both schizophrenia and bipolar disorder, NTNG2 mRNA was reduced in CA3, with reductions also found in CA4 and perirhinal cortex in bipolar disorder. The SNPs did not affect NTNGI or NTNG2 mRNA expression. Both NTNGI and NTNG2 mRNAs were developmentally regulated, and were unaltered by haloperidol, but NTNG2 mRNA was modestly increased by clozapine. These data implicate NTNGI and NTNG2 in the pathophysiology of schizophrenia and bipolar disorder, but do not support the hypothesis that altered mRNA expression is the mechanism by which genetic variation of NTNGI or NTNG2 may confer disease susceptibility.

Neuropsychopharmacology (2008) 33, 933-945; doi:I0.1038/sj.npp. I30 I457; published online 16 May 2007
\end{abstract}

Keywords: gene expression; hippocampus; in situ hybridization; isoform; netrin-GI; netrin-G2; splice variant; temporal cortex

\section{INTRODUCTION}

Netrin-G1 (NTNG1) and netrin-G2 (NTNG2), also known as laminet-1 and laminet-2, are vertebrate-specific axon guidance molecules. NTNG1 and NTNG2 undergo alternative splicing, generating 10 known isoforms for NTNG1, which mostly differ in the number of laminin-type epidermal growth factor (EGF)-like domains they contain (Nakashiba et al, 2000; Meerabux et al, 2005; Figure 1), while for NTNG2, three different isoforms have been identified (Nakashiba et al, 2002). Unlike classical secreted netrins, NTNG1 and NTNG2 are bound to the plasma membrane through a glycosyl phosphatidylinositol (GPI) anchor, and do not bind to known netrin receptors such as UNC-5H and DCC (Nakashiba et al, 2000, 2002; Yin et al, 2002). Instead, NTNG1 and NTNG2 bind to specific ligands called netrin-G1 ligand (NGL-1) and netrin-G2 ligand (NGL-2) respectively (Kim et al, 2006; Lin et al, 2003). Both NGL-1 and NGL-2 are membrane-bound post-synaptic proteins containing an intracellular PDZ (postsynaptic density-95/discs large/zona occludens-1) binding domain

*Correspondence: Dr SL Eastwood, University Department of Psychiatry, Neurosciences Building, Warneford Hospital, Headington, Oxford OX3 7JX, UK, Tel: + 441865 223620, Fax: + 44 1865 251076, E-mail: sharon.eastwood@psych.ox.ac.uk

Received 16 March 2007; revised 16 April 2007; accepted 17 April 2007 thought to be important in effecting downstream signaling events, and a leucine-rich repeat extracellular domain, which forms a horseshoe-shaped hook with which it binds to its pre-synaptic partner (Biederer, 2006). Together with their ability to promote neurite outgrowth and regulate synapse formation (Lin et al, 2003; Kim et al, 2006; Nakashiba et al, 2000, 2002), the structural characteristics of NTNG1 and NTNG2 and their ligands suggest that they may have functional similarities to the more extensively characterized neurexins and neuroligins, known to be important in synapse formation, function, and regulation of the balance between excitatory $v s$ inhibitory inputs (Chih et al, 2005; Dean and Dresbach, 2006; Lise and El-Husseini, 2006; Varoqueaux et al, 2006).

Schizophrenia is postulated to be a disorder of connectivity (Andreasen, 1999; Stephan et al, 2006) and of the synapse (Frankle et al, 2003; Mirnics et al, 2001; Moises et al, 2002) due, at least in part, to aberrant neurodevelopment (Lewis and Levitt, 2002; Marenco and Weinberger, 2000), with decrements in the number of synaptic contacts and/or synaptic activity being proposed as the possible substrate underlying altered functional connectivity in the disorder (Stephan et al, 2006; McGlashan and Hoffman, 2000). Of note, many of the recently identified potential susceptibility genes for schizophrenia play a role in synapse formation, functioning, and plasticity (Harrison and Owen, 2003; Harrison and Weinberger, 2005). Recently, single 


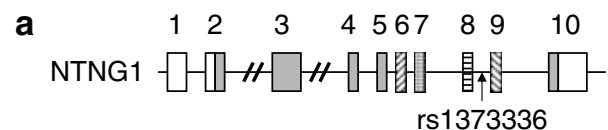

b
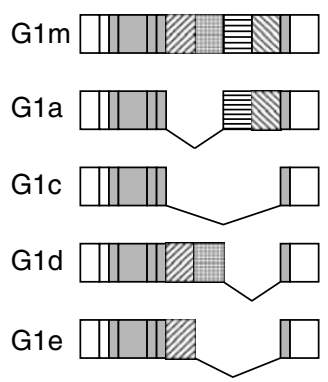

C

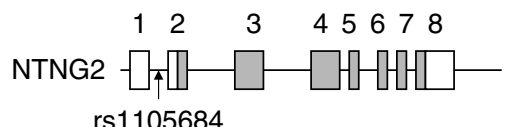

Figure I (a) Structure of the human NTNGI gene, showing the alternatively spliced exons 6-9, and the position of SNP rs/373336. The SNP tags a haplotype block that extends as far upstream as the third intron. The forward primer used to amplify GI isoforms was located in exon 4, with the reverse primer, and the ISHH probe, in exon 10. (b) NTNGI splice isoforms expressed in human brain. (c) Structure of the human NTNG2 gene and location of SNP rsI I05684. The ISHH probe spanned the exon 7/8 boundary, and is predicted to detect all NTNG2 splice variants based on the known mouse transcripts.

nucleotide polymorphisms (SNPs) in the genes for NTNG1 and NTNG2 have been reported to be associated with schizophrenia (Aoki-Suzuki et al, 2005; Fukasawa et al, 2004). Although these associations have yet to be replicated, the role of NTNG1 and NTNG2 in synapse formation and function enhances interest in these observations. As observed for other schizophrenia susceptibility genes (Harrison and Weinberger, 2005), the NTNG1 and NTNG2 SNPs associated with the disorder are either intronic and/or within untranslated regions, suggesting that any disease susceptibility they may confer occurs by altering some facet of the expression of the genes. NTNG1 mRNA isoform expression has been reported to be decreased in the dorsolateral prefrontal cortex in schizophrenia (AokiSuzuki et al, 2005). Here we have determined if NTNG1 and NTNG2 mRNA expression is influenced by schizophrenia and/or schizophrenia-associated SNPs. To address diagnostic specificity, subjects with bipolar disorder were included, and we examined a brain region implicated in both disorders, the temporal lobe, including the hippocampal formation and adjacent cortices (Arnold, 2000; Harrison, 1999, 2002, 2004; Vawter et al, 2000). Additionally, we determined if NTNG1 and NTNG2 mRNAs are developmentally regulated, and examined their expression in adult rat hippocampus after treatment with the antipsychotic drugs haloperidol, and clozapine.

\section{MATERIALS AND METHODS}

Different methodologies were used to examine NTNG1 and NTNG2 mRNA expression, their choice based upon previous findings, the question to be examined, and their relative abundance. Firstly, as the distribution of these mRNAs in the human temporal lobe had not been described, we used in situ hybridization histochemistry (ISHH) with oligonucleotide probes (specific for each gene and designed to detect all known GPI-anchored splice variants) to determine their regional and cellular distributions. ISHH was also used to examine NTNG1 and NTNG2 mRNA expression in the rat hippocampus during brain development, and in adult rats after antipsychotic treatment. To compare NTNG2 mRNA expression between diagnostic groups, ISHH using the same 'pan' probe was also employed, since (a) this allows subfields to be examined separately, and (b) the most significant diseaseassociated SNP, rs1105684, is in the $5^{\prime}$ untranslated region; this location suggests that the SNP is more likely to regulate total NTNG2 mRNA than it is to affect alternative splicing. In contrast, for NTNG1, based on the previous study (AokiSuzuki et al, 2005), we predicted that any change in its expression occurring in schizophrenia or related to the disease-associated SNP would affect the relative abundance of NTNG1 isoforms, not total NTNG1 mRNA. Moreover, our pilot ISHH experiments showed a limited distribution of the mRNA. Hence, we used RT-PCR with primers designed to detect all known NTNG1 GPI-anchored splice variants; in this way, the relative abundance of all NTNG1 transcripts expressed in the temporal lobe could be explored in one PCR, including less abundantly expressed transcripts which may not have been detected using less sensitive techniques. RT-PCR was also used to examine the developmental regulation of NTNG1 mRNA isoforms in human brain.

\section{Netrin-G1 and Netrin-G2 mRNA ISHH}

Post-mortem tissue from 35 subjects with schizophrenia, 34 with bipolar disorder, and 35 healthy comparison subjects was provided by the Stanley Medical Research Institute (SMRI) array collection (Table 1; see also http://www. stanleyresearch.org/programs/brain_collection.asp). Frozen sections $(14 \mu \mathrm{m})$ at the level of the mid-hippocampus, containing the hippocampal formation, perirhinal, and inferior temporal gyri, were pretreated for ISHH (Eastwood et al, 2000), and stored at $-20^{\circ} \mathrm{C}$ until use. ISHH for NTNG1 and NTNG2 mRNAs was carried out using ${ }^{35} \mathrm{~S} 3^{\prime}$-labelled oligonucleotide probes complementary to the human sequences (NTNG1: bases 1771-1810, Genbank accession number NM_014917.2; NTNG2: bases 1442-1480, Genbank accession number NM_032536.1) and established protocols (Eastwood et al, 2001). Sections were hybridized overnight at $37^{\circ} \mathrm{C}$ in hybridization buffer (Eastwood et al, 2000) containing 1 million c.p.m. purified labelled probe and $50 \mathrm{mM}$ dithiothreitol. Post-hybridization washes were carried out in $1 \times$ standard saline citrate for $3 \times 20 \mathrm{~min}$ at $60^{\circ} \mathrm{C}$, followed by $2 \times 60 \mathrm{~min}$ washes at room temperature. For NTNG2 mRNA, duplicate sections were run concurrently from all subjects. For NTNG1 mRNA, single sections from a subset of four male control subjects (age: 20-54 years; post-mortem interval (PMI); 6-27 h; brain $\mathrm{pH}$, 6.25-6.78) were hybridized for regional and cellular distribution analysis. Hybridized sections were placed against Kodak Biomax MR film (Amersham, Little Chalfont, UK) alongside 
Table I Demographics of Subjects Included in the Study

\begin{tabular}{|c|c|c|c|}
\hline & Controls & Schizophrenics & $\begin{array}{l}\text { Bipolar } \\
\text { disorder }\end{array}$ \\
\hline Gender (M:F) & $26: 9$ & $26: 9$ & $16: 18$ \\
\hline Age (years) & $44.2 \pm 7.6$ & $42.6 \pm 8.5$ & $45.4 \pm 10.7$ \\
\hline Brain pH & $6.61 \pm 0.27$ & $6.47 \pm 0.24$ & $6.43 \pm 0.30$ \\
\hline RIN & $4.72 \pm 1.56$ & $5.07 \pm 1.52$ & $4.89 \pm 1.82$ \\
\hline Post mortem delay (h) & $29.4 \pm 12.9$ & $31.4 \pm 15.5$ & $37.9 \pm 18.6$ \\
\hline $\begin{array}{l}\text { Onset of psychosis } \\
\text { (years) }\end{array}$ & - & $21.3 \pm 6.1$ & $25.3 \pm 9.2$ \\
\hline $\begin{array}{l}\text { Duration of illness } \\
\text { (years) }\end{array}$ & - & $21.3 \pm 10.1$ & $20.1 \pm 9.6$ \\
\hline $\begin{array}{l}\text { Total inpatient time } \\
\text { (years) }\end{array}$ & - & $1.23 \pm 2.25$ & $0.53 \pm 1.39$ \\
\hline $\begin{array}{l}\text { Lifetime fluphenazine } \\
\text { equivalents (mg) }\end{array}$ & - & $85000 \pm 100300$ & $10200 \pm 23200$ \\
\hline \multicolumn{4}{|l|}{ Alcohol use } \\
\hline Little or none & 18 & 10 & 4 \\
\hline Social & 12 & 7 & 8 \\
\hline Moderate past & I & 3 & 6 \\
\hline Moderate present & 2 & 3 & 3 \\
\hline Heavy past & 2 & 3 & 4 \\
\hline Heavy present & 0 & 9 & 8 \\
\hline Not known & 0 & 0 & । \\
\hline \multicolumn{4}{|l|}{ Drug use } \\
\hline Little or none & 30 & 14 & 11 \\
\hline Social & 4 & 4 & 4 \\
\hline Moderate past & 0 & 3 & 6 \\
\hline Moderate present & । & 3 & 3 \\
\hline Heavy past & 0 & 3 & 4 \\
\hline Heavy present & 0 & 6 & 6 \\
\hline Not known & 0 & 2 & I \\
\hline
\end{tabular}

Values are mean \pm SD. A significant effect of diagnosis was detected for brain $\mathrm{pH}$ $\left(F_{2,101}=4.17, P=0.018\right)$, with controls having higher $\mathrm{pH}$ than subjects with schizophrenia $(P=0.043)$ or bipolar disorder $(P=0.006)$. The groups were

matched for all other demographic variables, except for post mortem delay, in which controls had a significantly shorter mean post mortem delay than subjects with bipolar disorder $(P=0.028)$.

${ }^{14} \mathrm{C}$ microscales (NTNG1: 28 days; NTNG2: 21 days) and subsequently dipped in autoradiographic emulsion (LM1, Amersham), exposed for 16 weeks, developed, and stained with cresyl violet. Experimental controls consisted of ISHH with sense orientation probes, and incubation in the presence of 50 -fold excess unlabelled probe.

For the rat developmental studies, tissue was acquired from male animals killed (in accordance with UK Home Office guidelines) from six litter groups obtained from timed pregnancy Sprague-Dawley rats (Harlan Olac, UK) at embryonic day 19 (E19), postnatal day 3 (P3), P7, P14, P22, and P42 (Eastwood et al, 2005). Each time point contained between 3-5 animals. For the drug treatment study, adult male Sprague-Dawley rats (8 weeks, $250-300 \mathrm{~g}$; eight in each group) were administered $1 \mathrm{mg} / \mathrm{kg}$ haloperidol, $25 \mathrm{mg} / \mathrm{kg}$ clozapine, or saline by intraperitoneal injection once daily for 2 weeks (Law et al, 2004). No significant differences were found between the groups in their percentage weight gain over the 2 weeks, and the drug-treated rats did not appear to be sedated. Animals were killed $6 \mathrm{~h}$ after the final dose by lethal injection of pentobarbitone. For both rat studies, frozen coronal sections $(15 \mu \mathrm{m})$ were cut at the level of the dorsal hippocampus, collected onto Superfrost plus slides (VWR, Lutterworth, UK), pretreated (Eastwood et al, 2001), and ISHH performed for NTNG1 and NTNG2 mRNAs as described above. Triplicate sections were run concurrently for each transcript, and hybridized sections placed against Kodak Biomax MR film (Amersham) alongside ${ }^{14} \mathrm{C}$ microscales for the following times: NTNG1: 21 days; NTNG2: 14 days. Hybridized sections were subsequently dipped in photographic emulsion (LM1, Amersham), exposed for 4 weeks, developed and counterstained with cresyl violet.

\section{Image Analysis of ISHH Autoradiographs}

For the human study, NTNG2 mRNA autoradiographs were measured using an MCID Elite version 7.0 image analysis system (Interfocus, Haverhill, UK), calibrated to the ${ }^{14} \mathrm{C}$ microscales and corrected for non-specific signal. Measurements were taken over the granule cell layer of the dentate gyrus (DG), pyramidal cell layer of CA4 and CA3, and deep cortical layers of the perirhinal and inferior temporal cortex. Note that we use CA4 to refer to the invagination of the pyramidal cell layer into the 'jaws' of the DG (Duvernoy, 1998) and not to the polymorphic layer (hilus) (see Insausti and Amaral, 2004).

For the rat studies, NTNG1 and NTNG2, mRNA autoradiographs were measured as described above. For E19 rats, measurements were taken over the entire hippocampal formation, while for all other animals, measurements were taken over the DG granule cell layer and the pyramidal cell layer of CA3 and CA1. NTNG1 and NTNG2 mRNA measures during rat hippocampal development were normalized to the housekeeping gene glyceraldehyde-3-phosphate dehydrogenase (GAPDH) mRNA (Eastwood et al, 2005).

\section{Netrin-G1 mRNA Reverse-Transcriptase-PCR (RT-PCR)}

Total RNA was isolated from a section adjacent to those employed for NTNG2 mRNA ISHH, using Tri-Reagent (Sigma, Poole, UK) and established methods. RNA integrity number (RIN) was determined using an Agilent Bioanalyzer 2100 and RNA 6000 Nano chips (Agilent Technologies Wokingham, UK). Following pilot studies to determine the linear range of detection, $700 \mathrm{ng}$ of total RNA from each subject was DNAse-treated and reverse transcribed using 200 units of MMLV (Promega, Southampton, UK), 30 ng oligo(dT) primer, $0.5 \mathrm{mM}$ each dNTP (Promega) and 10 units RNAsin (Promega). Duplicate $30 \mathrm{ng}$ aliquots of the resulting cDNA samples were subjected to NTNG1 RT-PCR using PureTaq Ready-To-Go PCR beads (Amersham) and published primers (Aoki-Suzuki et al, 2005; Meerabux et al, 2005). Touchdown PCR amplification was performed as follows: an initial denaturing step at $94^{\circ} \mathrm{C}$ for $2 \mathrm{~min}$, followed by 20 amplification cycles; $30 \mathrm{~s}$ at $94^{\circ} \mathrm{C}$; $45 \mathrm{~s}$ at $70^{\circ} \mathrm{C}$ initially (minus $1^{\circ} \mathrm{C}$ at each cycle); $45 \mathrm{~s} 72^{\circ} \mathrm{C}$, followed by 15 amplification cycles; $30 \mathrm{~s} 94^{\circ} \mathrm{C} ; 45 \mathrm{~s} 55^{\circ} \mathrm{C} ; 45 \mathrm{~s} 72^{\circ} \mathrm{C}$, 
and a final extension step at $72^{\circ} \mathrm{C}$ for $7 \mathrm{~min}$. PCR products were measured using an Agilent 2100 Bioanalyzer and DNA 1000 chips (Agilent Technologies).

To examine changes in the relative expression of NTNG1 mRNA isoforms between fetal and adult human brain, RTPCR was performed as described above, using commercially available mRNA samples (Takara Bio Europe/Clontech, Saint-Germain-en-Laye, France) taken from adult temporal lobe (pooled from eight male/female Caucasians, aged 32-61 years), adult hippocampus (pooled from 20 male/female Caucasians aged 18-54) and from fetal brain (pooled from 21 male/female Caucasians aged 26-40 weeks).

\section{Netrin-G1c Isoform Quantitative Real-Time PCR}

To corroborate the above method, G1c transcript expression was also measured by quantitative real-time PCR (AB $7900 \mathrm{HT}$, Applied Biosystems, Warrington, UK) using previously published primers and a G1c isoform-specific minor groove-binding probe (Aoki-Suzuki et al, 2005). This was carried out in a subset of subjects for whom RNA was available (controls: $n=28$; age: $45 \pm 8$ (mean \pm SD); PMI: $31 \pm 13$; RIN: $4.8 \pm 1.6$; schizophrenia: $n=24$ : age: $44 \pm 9$ years; PMI: $29 \pm 15$; RIN: $5.2 \pm 1.6$; bipolar disorder: $n=27$; age: $47 \pm 11$ years; PMI: $36 \pm 20$; RIN: $4.9 \pm 1.8$ ). Triplicate reactions (each containing $10 \mathrm{ng}$ of cDNA template) were performed for all these subjects concurrently on a single plate. The mean absolute measures were calculated using a standard curve of serially diluted pooled cDNA and sequence detector software (SDS version 2, Applied Biosystems).

\section{Netrin-G1 and Netrin-G2 Genotype Determination}

DNA was extracted from cerebellar tissue using a Nucleon ST kit (Tepnel Life Sciences PLC, Manchester, UK). The most significantly associated SNP for each gene (as reported by Aoki-Suzuki et al, 2005 and Fukasawa et al, 2004), was chosen for genotyping (NTNG1: rs1373336; NTNG2: rs1105684). The NTNG1 SNP tags a $54 \mathrm{~kb}$ haplotype block that extends $43 \mathrm{~kb}$ upstream to intron 3 and spans the alternatively spliced region of the gene; the NTNG2 SNP tags a $16 \mathrm{~kb}$ haplotype block (Haploview, v.3.32). Genotype was determined using Applied Biosystems Taqman predesigned SNP genotyping assays in accordance with manufacturer's instructions. Genotype reproducibility was greater than $99 \%$.

\section{Statistical Analysis}

All statistical analyses were performed using SPSS version 13 software. One sample Kolmogorov-Smirnov tests were used to verify that the data were normally distributed.

For the human post-mortem studies, two-way analysis of covariance (ANCOVA) was performed to look for overall effects of diagnosis and isoform (NTNG1) or subfield (NTNG2), and their interaction. Subsequently, one-way ANCOVAs were performed for each isoform (NTNG1) or subfield (NTNG2), with planned comparisons between diagnostic groups explored using least significant difference (LSD). Effects of genetic variation on NTNG1 and NTNG2 mRNA expression were also examined using ANCOVA. For all the ANCOVAs, three covariates were chosen, a priori, based upon their frequent influence upon mRNA detection (eg Barton et al, 1993; Harrison et al, 1995): age, postmortem delay, and RIN (Imbeaud et al, 2005). RIN was chosen as the measure of RNA quality instead of brain $\mathrm{pH}$, formerly widely used, since RIN is a direct rather than proxy measure, and explains a greater proportion of the variance (Lipska et al, 2006; Stan et al, 2006, and our unpublished observations). In addition to these primary analyses, we also carried out secondary analyses to assess the robustness of our findings: in particular, we re-ran the ANCOVAs, limiting the covariates to those that had a significant influence for each dataset (ie subfield or isoform) as determined by Spearman correlations $(p<0.05)$. The latter were also used to examine relationships with other continuous variables (eg inpatient time, lifetime antipsychotic exposure). Finally, the potential influence of smoking, alcohol, and substance misuse, as rated by the SMRI, was evaluated using ANOVA. Smoking was classified into three categories (smokers, ex-smokers, or non-smokers), while six categories were used for alcohol and substance use (little or none, social, moderate past, moderate present, heavy past, heavy present). All experiments were performed (by SLE) blind to all clinical information; PJH retains the SMRI code.

For the rat hippocampal development data, ANOVA was used to determine if there was a significant overall effect of age on the expression of each transcript for each region examined. Where significant effects of age were detected, Dunnett $t$-tests were used to determine if NTNG1 and NTNG2 mRNA expression at each post natal age differed from that when each of the expression of each transcript was first detected. In addition, post hoc Scheffe comparisons were made between each age group and every other group to detect periods of transient changes in relative expression.

For the rat antipsychotic administration study, a two-way ANOVA was used, with drug and hippocampal subfield as factors. Subsequently, one-way ANOVAs were performed for each subfield, with differences between drug treated and control animals explored using LSD. In all instances significance was set as $P=0.05$.

\section{RESULTS}

\section{Regional and Cellular Expression of Netrin-G1 and Netrin-G2 mRNAs in Human Temporal Cortex}

Using pan probes specific for each gene, NTNG1 and NTNG2 mRNAs were detected in the human temporal cortex. Minimal background signal was seen for sections incubated in the presence of excess cold unlabelled probe, or after hybridization with probes in the sense direction (data not shown).

Regionally, no NTNG1 mRNA signal was detected in the hippocampus proper, with low to moderate signal observed over the subiculum, parahippocampal gyrus, and perirhinal and inferior temporal cortex (Figure 2a). Examination of dipped sections revealed that NTNG1 mRNA was expressed in occasional hippocampal interneurons (Figure 3a), and some subicular pyramidal neurons (Figure $3 \mathrm{~b}$ ). In the perirhinal and inferior temporal cortex, NTNG1 mRNA was mostly localized over layer 3 neurons (Figure 3c). 

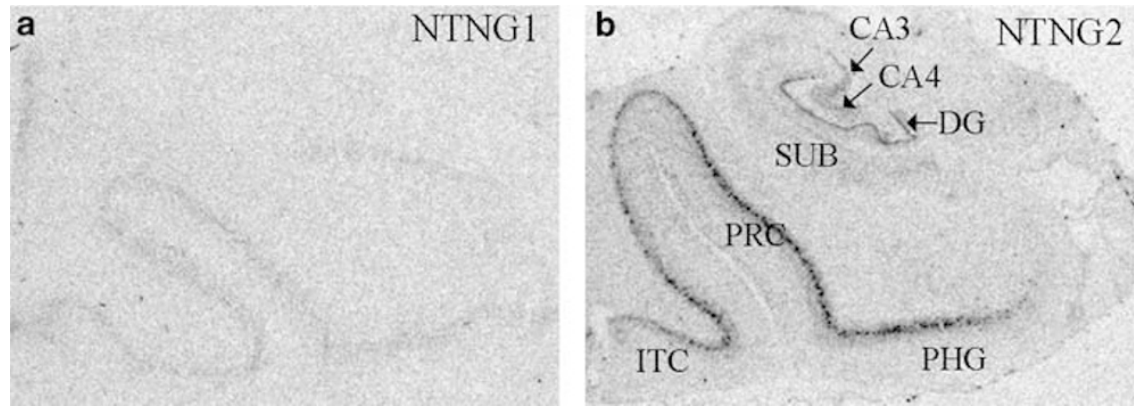

Figure 2 Regional distribution of (a) NTNGI and (b) NTNG2 mRNAs in the temporal lobe of representative control subjects. CA: cornu ammonis; DG: dentate gyrus; ITC: inferior temporal cortex; SUB: subiculum: PHG: parahippocampal gyrus; PRC: perirhinal cortex. Although NTNG2 mRNA was observed in the PHG of some subjects (as seen here), its variable expression between individuals precluded quantitative analyses.

NTNG2 mRNA was abundant in DG, CA4, and CA3, and the deep layers of the perirhinal and inferior temporal cortex. Signal was moderate in CA1, minimal in the subiculum, and variable in the parahippocampal cortex (Figure 2b). At the cellular level, NTNG2 mRNA was concentrated over DG granule cells and pyramidal neurons in each subfield, but was not convincingly observed over putative interneurons (data not shown). In the perirhinal and inferior temporal cortex, NTNG2 mRNA was strongly expressed by neurons in deep layer 5 and layer 6 (Figure 3d).

In summary, both NTNG1 and NTNG2 mRNAs are predominantly expressed by excitatory neurons in the human temporal cortex, but are concentrated in different cell populations and areas of the temporal lobe, and with NTNG1 mRNA also being expressed by some putative inhibitory neurons. Overall, NTNG2 mRNA is more abundantly expressed than NTNG1 mRNA.

\section{Regional and Cellular Expression of Netrin-G1 and Netrin-G2 mRNAs in Rat Hippocampal Formation}

As in the human, in the rat hippocampus NTNG2 mRNA was more abundant than NTNG1 mRNA, though some species differences in the distribution of NTNG1 and NTNG2 mRNAs between rats and humans were found. For example, in contrast to humans, NTNG1 mRNA was expressed at relatively high levels in the adult rat DG (Figures $3 \mathrm{e}$ and $4 \mathrm{~d}$ ). In addition, at the cellular level in the adult rat, NTNG1 mRNA was localized over the pyramidal layer of CA1 and granule cells of the DG, and was also expressed by hippocampal interneurons (Figure 3e). Expression of NTNG1 mRNA in CA1 was especially prominent during early hippocampal development (Figure 4a-d).

As observed in humans, NTNG2 mRNA was more abundantly expressed than NTNG1 mRNA, though it was expressed at relatively high levels throughout most hippocampal subfields (Figure 4e-j), with NTNG2 mRNA concentrated over granule cells of the DG (Figure $3 \mathrm{f}$ ) and pyramidal neurons in CA3 and CA1, but not convincingly over putative interneurons (Figure $3 \mathrm{f}$ ).

\section{NTNG1 Isoform Expression during Human Brain Development}

Developmental changes in NTNG1 isoform expression were examined in humans using total RNA from fetal brain and
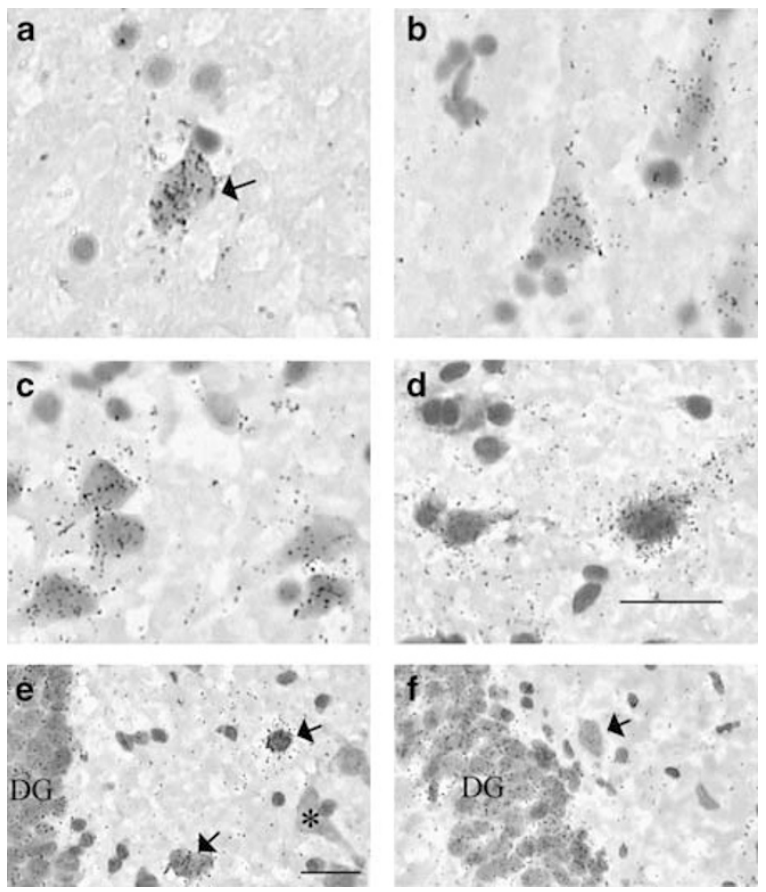

Figure 3 Cellular expression of (a-c, e) NTNGI and (d, f) NTNG2 mRNAs in (a-d) human temporal lobe and (e, f) P42 rat hippocampal formation. (a) NTNGI mRNA is expressed by occasional putative hippocampal interneurons (arrow), as observed here in the stratum oriens of CA3. (b) NTNGI mRNA over pyramidal neurons in the subiculum. (c) NTNGI mRNA expression by layer 3 perirhinal cortical neurons. (d) NTNG2 mRNA in the perirhinal cortex is localized over deep layer 5/6 neurons. (e) NTNGI mRNA is expressed by granule cells of the rat DG, and by putative interneurons (arrows), but is not reliably detected over pyramidal neurons (asterisk). (f) NTNG2 mRNA is expressed by granule cells of the rat DG, but is not reliably detected over putative hippocampal interneurons (arrow). Bars in (d) and (e) $=30 \mu \mathrm{m}$. Abbreviations as in Figure 2.

adult hippocampus and temporal cortex. Semi-quantitative RT-PCR detected several PCR products of the predicted sizes. In fetal brain and adult temporal cortex, these corresponded to G1c, G1d, G1e, and G1m while in adult hippocampus, an additional band corresponding to Gla was detected (data not shown). The four NTNG1 isoforms that were detected in all samples examined (G1c, G1d, G1e, G1m), expressed as a percentage of their sum abundance, is shown in Figure 5. While G1c, G1d, G1e, and G1 m are all detected from early brain development onwards, the relative expression of each isoform changes in adulthood (Figure 5). 

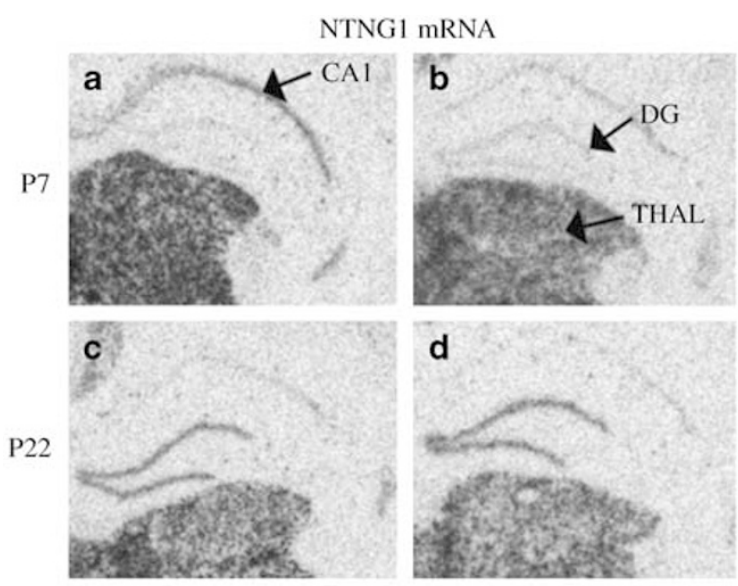

P42

NTNG2 mRNA
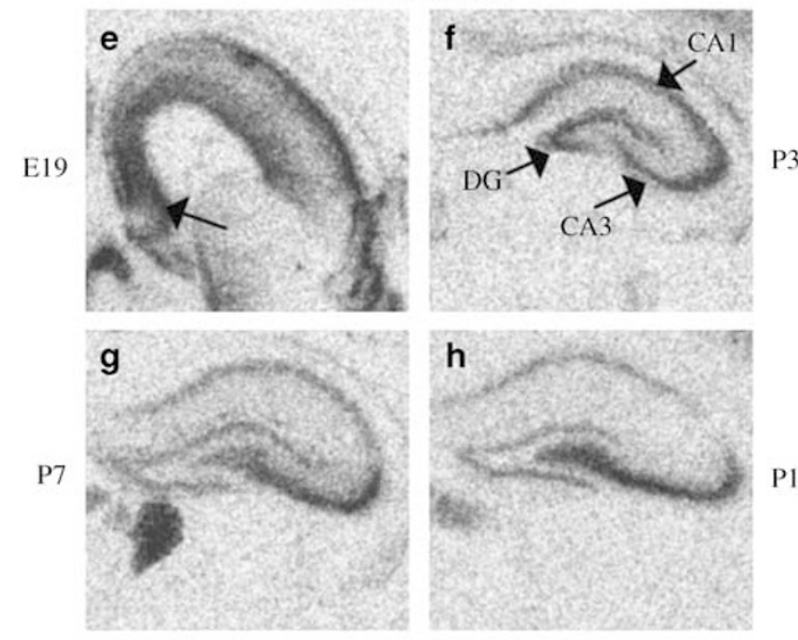

P14
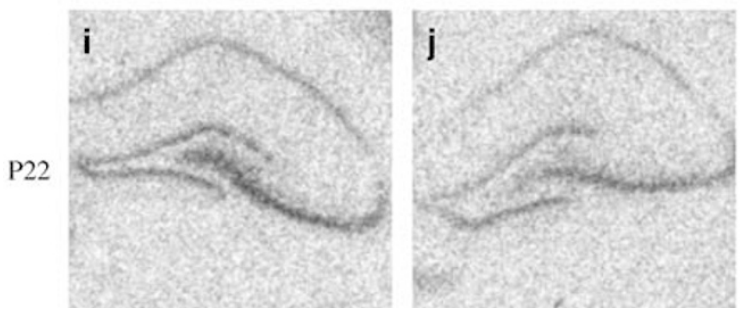

Figure 4 Representative autoradiographic images demonstrating the regional distribution of $(a-d)$ NTNGI and $(e-j)$ NTNG2 mRNAs in the developing rat hippocampus. Arrow in (e) indicates the location of the developing hippocampus. NTNGI mRNA was not detected in the hippocampus at EI9 (not shown), and was first detected in CAI at P3 (not shown). At P7 (a) NTNGI mRNA was also detected in the DG. Note that NTNGI mRNA expression in the DG increases with age, while that in CAI decreases. As reported previously (Nakashiba et al, 2000; Yin et al, 2002) NTNGI mRNA is strongly expressed in the thalamus. NTNG2 mRNA was detected from EI9 onwards and is robustly expressed in most hippocampal subfields. THAL: thalamus. Other abbreviations as in Figure 2.

Of note, the relative abundance of G1c and G1d shifts with development, with G1c becoming the predominant isoform in adult hippocampus and temporal cortex.

\section{Developmental Changes in Netrin-G1 and Netrin-G2 mRNAs in Rat Hippocampus}

Developmental shifts in expression of NTNG1 and NTNG2 mRNAs were seen in the rat hippocampus (Table 2), with a

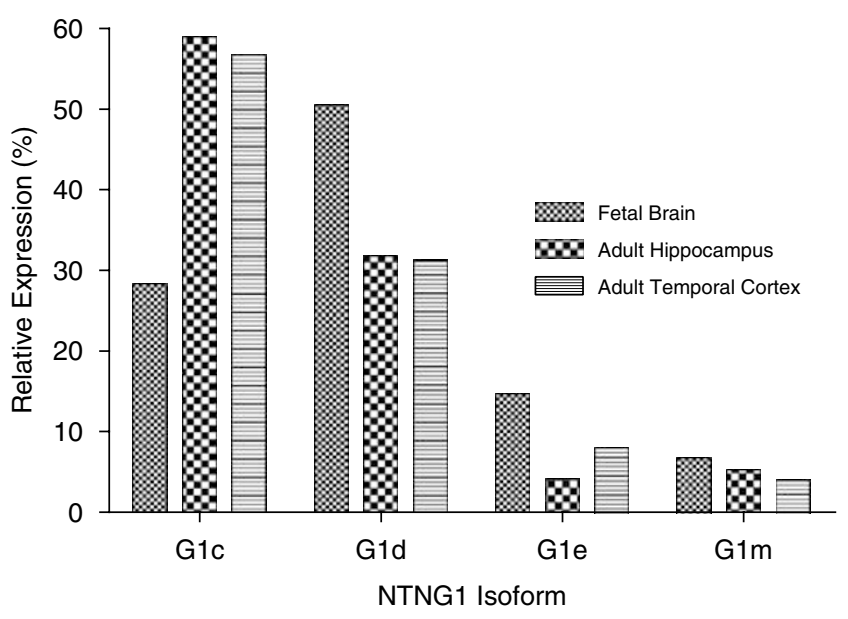

Figure 5 Relative expression of NTNGI isoform mRNAs during human brain development. Four isoforms ( $G|c, G| d, G \mid$ e, and $G \mid m$ ) were reliably detected in fetal brain and adult hippocampus, and temporal cortex. The relative abundance (expressed as a percentage of the sum of all four mRNAs quantified) of GIc increased, and that of GId decreased, between fetal and adult brain.

profile that differed between subfields and transcripts. NTNG1 mRNA was first detected reliably at P3. In the DG, NTNG1 mRNA was weakly expressed until P14, with significant increases between P14 and P22 $(P=0.046)$, and between P22 and P42 $(P<0.001)$. In CA1, NTNG1 mRNA decreased between P7 and P14 $(P=0.005)$. For NTNG2, mRNA signal decreased steadily in CA1 from E19 to P14, but increased in DG between E19 and P3 $(P=0.016)$, and again between P22 and P42 $(P=0.037)$. In CA3, NTNG2 mRNA increased between P3 and P7 $(P=0.001)$, after which it decreased, reaching significance between P14 and P22 $(P=0.002)$.

\section{Netrin-G1 mRNA Isoform Expression in Schizophrenia and Bipolar Disorder}

Using the same semi-quantitative RT-PCR method as utilized in the study of NTNG1 isoform expression during human brain development described above, five NTNG1 PCR products (G1a, G1c, G1d, G1e, and G1 m) were readily detectable in adult human temporal lobe from the Stanley Medical Research Institute array collection (Figure 6).

Two-way ANCOVA (with age, post-mortem delay and RIN as covariates) demonstrated a significant effect of diagnosis $\quad\left(\mathrm{F}_{2,497}=3.88, \quad P=0.021\right) \quad$ and isoform $\left(\mathrm{F}_{4,497}=276.59, P<0.001\right)$, and a significant diagnosisby-isoform interaction $\left(\mathrm{F}_{8,497}=2.25, \mathrm{P}=0.023\right)$, on NTNG1 mRNA. Subsequent one-way ANCOVAs revealed a significant effect of diagnosis upon G1c mRNA, but not for any other isoform (Table 3). As shown in Figure 7, G1c mRNA was significantly decreased in bipolar disorder subjects as compared to controls, with a similar trend in schizophrenia that became significant $(P=0.037)$ if the analysis was repeated with the omission of the one outlier (defined as $>2$ SDs from the group mean). We also quantified G1c mRNA in a subset of subjects using $\mathrm{qPCR}$ to assess the quantitative nature of our RT-PCR method. A significant correlation was detected between G1c mRNA measures using cDNA obtained from the same reverse transcription reaction for each subject $(r=0.844, P<0.001)$. These 
Table 2 Summary of Developmental Changes in NTNGI and NTNG2 mRNAs During Rat Hippocampal Development

\begin{tabular}{|c|c|c|c|c|c|c|c|}
\hline Age & & EI9 & P3 & P7 & PI4 & $\mathbf{P 2 2}$ & P42 \\
\hline DG & $F_{5,19}=28.30, P<0.001$ & - & $0.030(0.013)$ & $0.029(0.009)$ & $0.037(0.014)$ & $0.074(0.023)$ & $0.189(0.045)$ \\
\hline CAI & $F_{5,19}=9.39, P=0.001$ & - & $0.099(0.025)$ & $0.096(0.019)$ & $0.047(0.028)$ & $0.024(0.004)$ & $0.044(0.013)$ \\
\hline DG & $F_{5,18}=7.42, P=0.001$ & $0.231(0.052)$ & $0.333(0.067)$ & $0.219(0.032)$ & $0.137(0.017)$ & $0.133(0.027)$ & $0.220(0.096)$ \\
\hline CA3 & $F_{5,19}=12.64, P<0.001$ & $0.231(0.052)$ & $0.211(0.038)$ & $0.288(0.007)$ & $0.24 \mid(0.020)$ & $0.161(0.013)$ & $0.142(0.028)$ \\
\hline CAI & $F_{5,19}=17.39, P<0.001$ & $0.231(0.052)$ & $0.173(0.028)$ & $0.126(0.016)$ & $0.082(0.016)$ & $0.080(0.009)$ & $0.096(0.030)$ \\
\hline
\end{tabular}

NTNG I

DG

CAI

NTNG2

DG

CA3

CAI
Change in expression relative to when first detected

$(\downarrow)$

$(\downarrow)$ $(\uparrow)$

$\downarrow^{\dagger}$ $(\uparrow)$

$\downarrow^{\ddagger} \quad \downarrow^{\dagger}$

Values and mean (SD), normalized to GAPDH mRNA. Post hoc comparisons between developmental age when mRNA is first detected (NTNGI: P3; NTNG2: EI9) and subsequent age groups.

$* P<0.05,{ }^{\dagger} P<0.02,{ }^{\ddagger} P<0.01$. Symbols in parenthesis denote non-significant change.

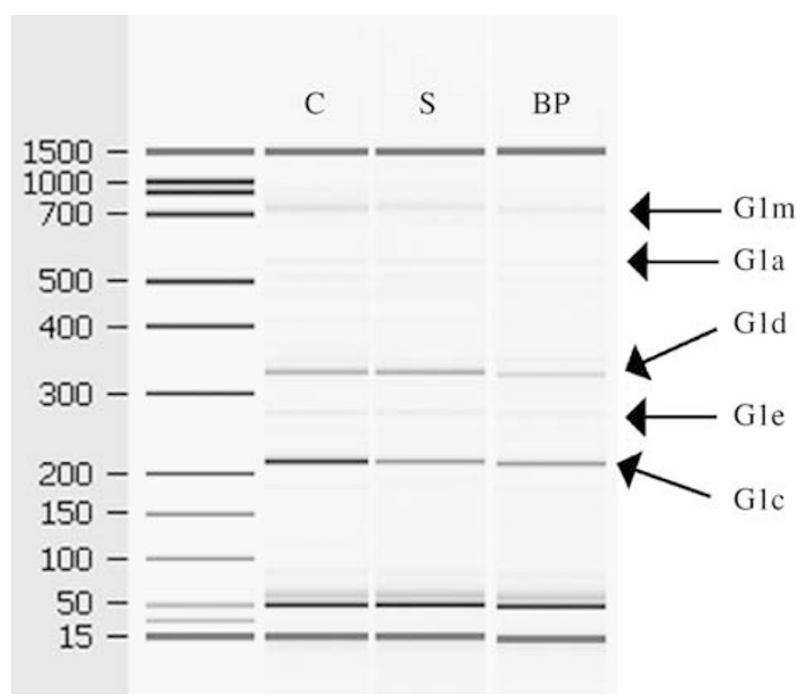

Figure 6 Examples of gel-like images produced by the Agilent 2100 bioanalyzer for semi-quantitative analysis of NTNGI mRNA using RT-PCR, showing a representative control subject (C), a subject with schizophrenia (S), and a bipolar disorder subject (BP). Bands of the predicted size (ladder on left) corresponding to the Gla, GIc, GId, Gle, and GIm isoforms were detected.

findings, together with the absence of any change in the expression of the other NTNG1 isoforms examined, indicate that decreased G1c mRNA is unlikely to be due to any chance difference between the groups in the amount of starting mRNA used.

The abundance of all NTNG1 isoforms correlated with RIN $(R \geqslant 0.245, P<0.013)$, and all except G1e also correlated with brain $\mathrm{pH}(R \geqslant 0.294, P<0.003)$, but there were no correlations with age nor post-mortem delay $(R \leqslant-0.138$, $P \geqslant 0.165)$. As described in the Materials and methods, for our secondary analyses we therefore repeated the ANCOVAs using only RIN, and $\mathrm{pH}$ for all isoforms except G1e, as the covariates. This retained the significant diagnosis-by-isoform interaction, but the reduced G1c mRNA expression in bipolar disorder became non-significant (data not shown). NTNG1 isoform expression did not correlate with lifetime antipsychotic drug exposure nor total inpatient time in either subjects with schizophrenia or bipolar disorder, except for Gle mRNA expression in schizophrenia, which correlated significantly with lifetime drug exposure $(r=-0.453, P=0.007)$. Alcohol, substance misuse, and smoking had no significant effects upon NTNG1 isoform expression (data not shown).

\section{Netrin-G2 mRNA Expression in Schizophrenia and Bipolar Disorder}

Two-way ANCOVA (with age, post-mortem delay, and RIN as covariates) detected significant effects of diagnosis $\left(\mathrm{F}_{2,494}=3.707, \quad P=0.025\right)$ and subfield $\left(\mathrm{F}_{4,494}=191.27\right.$, $P<0.001)$ upon NTNG2 mRNA, but with no diagnosisby-subfield interaction $\left(\mathrm{F}_{8,494}=0.57, P=0.801\right)$. Nevertheless, one-way ANCOVAs were performed for each subfield, and showed that diagnosis had a significant effect on NTNG2 mRNA in CA4 and CA3, with a trend in the perirhinal cortex, and no changes in DG or inferior temporal cortex (Figure 7b-f). In CA4 (Figure 7c) and perirhinal cortex (Figure 7e), NTNG2 mRNA was reduced in bipolar disorder as compared to control subjects, while in CA3 (Figure 7d), NTNG2 mRNA was decreased in subjects with bipolar disorder and schizophrenia. 
Table 3 NTNGI Isoform Expression in the Temporal Cortex in Controls and Subjects with Schizophrenia or Bipolar Disorder

\begin{tabular}{|c|c|c|c|c|}
\hline & ANCOVA $^{a}$ & Control & Schizophrenia $^{b}$ & Bipolar disorder \\
\hline Gla & $F_{2,97}=0.56, P=0.57 \mathrm{I}$ & $0.16 \pm 0.17$ & $0.15 \pm 0.17$ & $0.16 \pm 0.19$ \\
\hline GIC & $F_{2,97}=3.60, P=0.031$ & $4.83 \pm 2.41$ & $4.12 \pm 2.07$ & $3.66 \pm 1.92 *$ \\
\hline Gld & $F_{2,97}=0.03, P=0.971$ & $1.35 \pm 0.78$ & $1.51 \pm 0.89$ & $1.44 \pm 1.14$ \\
\hline Gle & $F_{2,97}=1.74, P=0.181$ & $0.26 \pm 0.16$ & $0.21 \pm 0.13$ & $0.22 \pm 0.13$ \\
\hline GIm & $F_{2,97}=1.24, P=0.294$ & $0.68 \pm 0.48$ & $0.63 \pm 0.45$ & $0.56 \pm 0.50$ \\
\hline
\end{tabular}

Values are mean $(n g / \mu l) \pm S D$.

a With age, post-mortem delay and RIN as covariates. $* P=0.01$ as compared to controls.

b One subject with schizophrenia was omitted from the study due to amplification failure.

Significant inverse correlations between age and NTNG2 mRNA were detected in CA4 $(R=-0.234, P=0.017)$, CA3 $(R=-0.209, P=0.033)$ and the inferior temporal gyrus $(R=-0.306, P=0.002)$. Brain $\mathrm{pH}$ correlated with NTNG2 mRNA in most subfields $(R \geqslant 0.216, P \leqslant 0.033)$ except DG $(R=0.129, P=0.192)$, while RIN correlated with NTNG2 mRNA signal in all subfields $(R \geqslant 0.202, P \leqslant 0.047)$. When the ANCOVAs were repeated including only the significantly correlated variables as covariates, the significant effects of diagnosis seen in CA4, CA3 and perirhinal cortex remained, and no additional significant effects emerged.

Lifetime antipsychotic exposure correlated inversely with NTNG2 mRNA in DG $(r=-0.336, P=0.049)$, CA4 $(r=-0.448, P=0.007)$, CA3 $(r=-0.382, P=0.024)$, and inferior temporal cortex $(r=-0.38, P=0.032)$ in schizophrenia. Total inpatient time did not correlate with NTNG2 mRNA. Neither smoking nor alcohol had any significant effects upon NTNG2 mRNA in any subfield. Substance misuse affected NTNG2 mRNA in CA4 $\left(\mathrm{F}_{5,61}=4.209\right.$, $P=0.002)$ and CA3 $\left(\mathrm{F}_{5,61}=4.476, P=0.002\right)$, with expression being lower in subjects with no history of misuse.

\section{Schizophrenia Associated SNPs and Netrin-G1 and Netrin-G2 mRNA Expression}

Genotypes for the two SNPs examined, rs1373336 and rs1105684, were in Hardy-Weinberg equilibrium in each diagnostic group. NTNG1 and NTNG2 mRNAs were not influenced by the respective disease associated SNPs examined, and no genotype-by-diagnosis interactions were detected (Table 4).

\section{Effects of Antipsychotic Drug Treatment on Netrin-G1 and Netrin-G2 mRNAs in Rat Hippocampus}

Two-way ANOVA showed that 2 weeks' antipsychotic drug treatment did not affect NTNG1 mRNA expression $\left(\mathrm{F}_{5,42}=0.521, P=0.598\right)$, but did influence NTNG2 mRNA $\left(\mathrm{F}_{8,63}=4.49, P=0.015\right)$. Subsequent one-way ANOVAs demonstrated that NTNG2 mRNA was unaffected by haloperidol, while small but significant increases in NTNG2 mRNA were detected in the DG and CA1 with clozapine (Table 5).

\section{DISCUSSION}

The main findings of this study are: (1) NTNG1 and NTNG2 mRNAs have distinct regional and cellular distributions in the human medial and inferior temporal lobe. (2) Both genes are differentially expressed during rat hippocampal development, and NTNG1 isoforms are developmentally regulated in human brain. (3) Of the five NTNG1 mRNA isoforms detected, G1c mRNA was selectively decreased in bipolar disorder and schizophrenia. (4) NTNG2 mRNA expression was decreased in CA3 in bipolar disorder, and schizophrenia, and additionally in CA4 and perirhinal cortex in bipolar disorder. (5) No association was found between NTNG1 and NTNG2 mRNA expression and the two schizophrenia-associated SNPs examined. (6) NTNG1 and NTNG2 mRNAs in the rat hippocampus were unaffected by haloperidol administration and modestly increased by clozapine. These findings add to the candidacy of NTNG1 and NTNG2 involvement in the pathophysiology of schizophrenia, and also suggest a role in bipolar disorder. Decreased NTNG1 and NTNG2 mRNA expression may contribute to the synaptic involvement noted in both disorders, but do not shed any light on the molecular basis of their putative genetic association.

\section{Distribution of Netrin-G1 and Netrin-G2 mRNAs in the Human Temporal Lobe}

To our knowledge, the distribution of NTNG1 and NTNG2 mRNAs in the human temporal lobe has not been described previously. As reported in rodents (Kim et al, 2006; Nakashiba et al, 2002; Yin et al, 2002) and monkey (Miyashita et al, 2005), NTNG2 mRNA was the more widely and abundantly expressed (Figure 2). Minimal NTNG1 mRNA signal was detected in the hippocampus proper (Figure 2a), except for expression by occasional scattered non-pyramidal neurons (Figure 3a), while NTNG2 mRNA was reliably detected in granule cells of the DG and in the pyramidal cell layers of CA4 and CA3. In the perirhinal and inferior temporal cortex, wherein both genes are expressed, NTNG1 mRNA was localized over layer 3 (Figure 3c), while NTNG2 mRNA expression was limited to layer 5/6 neurons (Figure 3d). Although it is difficult to distinguish deep layer 5 neurons from those in layer 6 , the reported expression of NTNG2 mRNA by layer 6 neurons in monkey cortex (Miyashita et al, 2005) makes it likely that neurons we observed expressing NTNG2 mRNA are also layer 6 neurons.

In summary, both regionally and cellularly, NTNG1 and NTNG2 mRNA expression was essentially non-overlapping. As previously suggested, for rodents (Kim et al, 2006; Nakashiba et al, 2002), the differential expression of NTNG1 and NTNG2 mRNAs in the human temporal lobe implies non-redundant, distinct functions for these axon guidance molecules. 
a
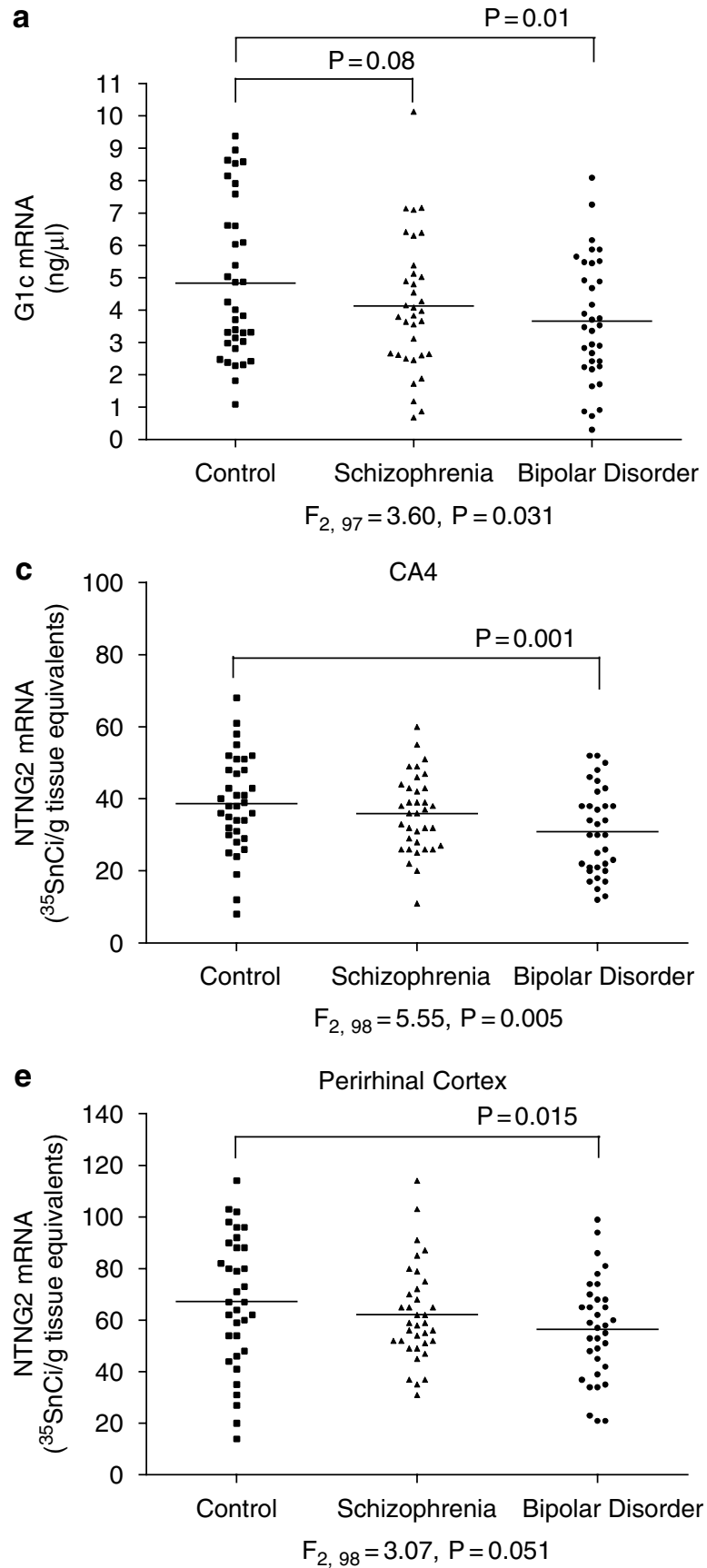

b

Dentate Gyrus

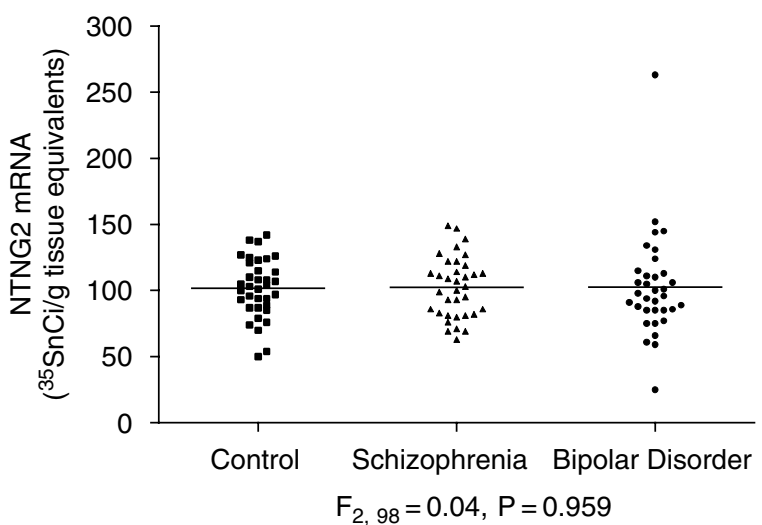

d

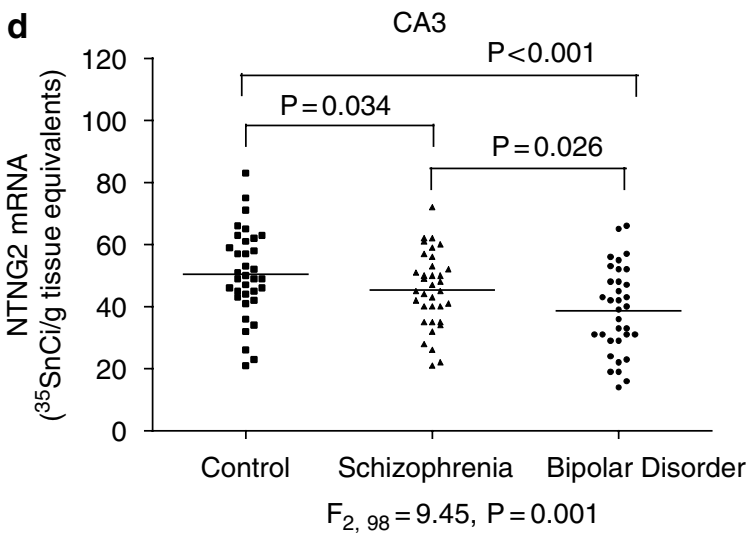

f Inferior Temporal Cortex

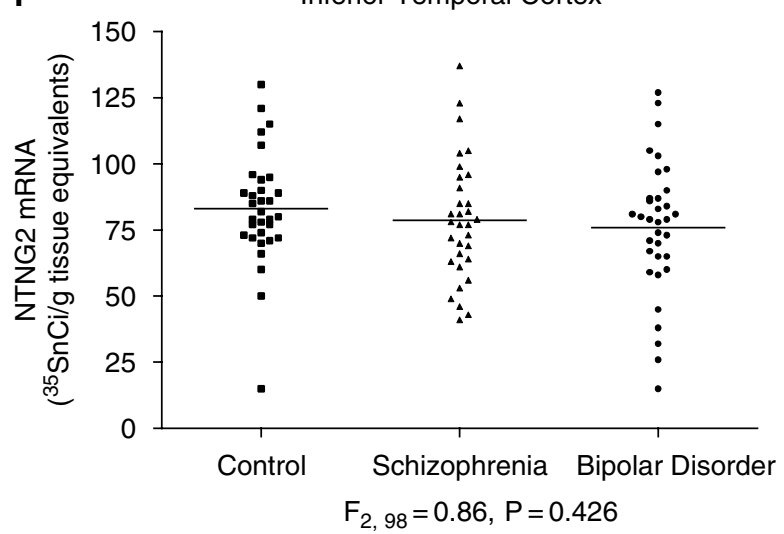

Figure 7 Quantitative analyses of NTNGI and NTNG2 mRNA expression in the temporal lobe in controls (squares), subjects with schizophrenia (triangles), and subjects with bipolar disorder (circles). (a) GIc isoform of NTNGI mRNA in homogenized temporal cortex tissue. One subject with schizophrenia was omitted from the GIc study due to amplification failure. (b-f) NTNG2 mRNA in subfields of the temporal lobe.

\section{Netrin-G1 and Netrin-G2 mRNA Expression is Developmentally Regulated}

NTNG1 and NTNG2 mRNA expression was examined during rat hippocampal development from E19 to P42, a period of time roughly corresponding in humans from the later part of the first trimester of pregnancy to early adulthood (Clancy et al, 2001). Our data show that NTNG1 and NTNG2 mRNAs are developmentally regulated. Both NTNG1 and NTNG2 mRNAs were expressed during early hippocampal development, though that for NTNG1 was not detected in the hippocampus until P3. The difference in the timing between the first detection of NTNG1 and NTNG2 mRNAs could be taken as supportive of different functional roles for NTNG1 and NTNG2, but may also reflect a lack of sensitivity for ISHH to detect the less abundantly expressed gene. Regardless, the expression of both genes during early hippocampal development is consistent with other findings indicating the importance of NTNG1 and NTNG2 in guiding synapse formation and neurodevelopment (Kim et al, 2006; Nakashiba et al, 2002), and suggests that NTNG1 and NTNG2 may exert some of their pathogenic influence on schizophrenia and bipolar disorder during this time period. 
Table 4 NTNGI and NTNG2 Genotype is not Associated with mRNA Expression

NTNGI isoform mRNA expression $(\mathrm{ng} / \mu \mathrm{l})^{\mathrm{a}}$

\begin{tabular}{lcccccc}
\hline Genotype (rs|373336) & N & Gla & GIc & GId & Gle & GIm \\
\hline$C / C$ & 25 & $0.14 \pm 0.15$ & $4.04 \pm 2.00$ & $1.24 \pm 0.70$ & $0.23 \pm 0.15$ & $0.54 \pm 0.40$ \\
$C / T$ & 53 & $0.14 \pm 0.15$ & $4.09 \pm 2.18$ & $1.38 \pm 0.95$ & $0.23 \pm 0.15$ & $0.60 \pm 0.51$ \\
$T / T$ & 25 & $0.20 \pm 0.20$ & $4.64 \pm 2.35$ & $1.74 \pm 1.10$ & $0.23 \pm 0.15$ & $0.76 \pm 0.50$
\end{tabular}

NTNG2 mRNA expression $\left({ }^{35} \mathrm{SnCi} / g\right.$ tissue equivalents)

\begin{tabular}{lcccccc}
\hline Genotype (rsI 1 05684) & N & DG & CA4 & CA3 & Perirhinal cortex & Inferior temporal cortex \\
\hline A $A$ A & 74 & $100.9 \pm 24.1$ & $34.9 \pm 12.9$ & $44.3 \pm 13.8$ & $61.5 \pm 20.6$ & $78.1 \pm 22.4$ \\
A T & 26 & $109.4 \pm 37.2$ & $36.3 \pm 12.2$ & $46.7 \pm 14.8$ & $63.6 \pm 21.4$ & $84.1 \pm 29.6$ \\
T/T & 4 & $79.6 \pm 37.8$ & $33.1 \pm 14.2$ & $44.5 \pm 18.0$ & $65.4 \pm 37.4$ & $69.9 \pm 24.4$ \\
\hline
\end{tabular}

Values are mean $\pm S D$.

${ }^{a}$ One subject was omitted due to NTNGI RT-PCR failure.

Table 5 Effect of Antipsychotic Drug Treatment on NTNGI and NTNG2 mRNAs in Rat Brain

\begin{tabular}{|c|c|c|c|c|c|}
\hline MRNA & Area & Effect of drug & Saline $(n=8)$ & Haloperidol $(n=8)$ & Clozapine $(n=8)$ \\
\hline \multirow[t]{2}{*}{ NTNGI } & DG & $F_{2,21}=0.708, P=0.504$ & $477 \pm 31$ & $451 \pm 23$ & $458 \pm 54$ \\
\hline & CAI & $F_{2,21}=0.418, P=0.663$ & $102 \pm 23$ & $108 \pm 25$ & $98 \pm 17$ \\
\hline \multirow[t]{3}{*}{ NTNG2 } & DG & $F_{2,21}=3.069, P=0.068$ & $384 \pm 42$ & $394 \pm 34$ & $428 \pm 37 *$ \\
\hline & CA3 & $F_{2,21}=0.727, P=0.494$ & $328 \pm 28$ & $316 \pm 28$ & $334 \pm 37$ \\
\hline & CAI & $F_{2,21}=2.236, P=0.132$ & $152 \pm 25$ & $163 \pm 23$ & $175 \pm 17 * * *$ \\
\hline
\end{tabular}

Values are ${ }^{35} \mathrm{SnCi} / \mathrm{g}$ tissue equivalents (mean $\pm \mathrm{SD}$ ).

$* P=0.027, * * P=0.047$, as compared to saline controls.

We also examined the relative expression of NTNG1 mRNA isoforms in human fetal and adult brain and confirmed previous findings that these isoforms are developmentally regulated (Meerabux et al, 2005). In both studies, G1d is the predominant isoform in fetal brain, while G1c is the most abundantly expressed isoform in adult brain; the expression of Gle mRNA is also reduced in adult as compared to fetal brain, while Gla mRNA expression increases during brain development. Functional differences between the various NTNG1 isoforms have not been explored, though the suggestion that differences in the number of EGF-like domains regulates the quantity and variety of binding partners (see Mitsui et al, 2002) implies that EGF domain number differences between NTNG1 isoforms may confer different binding properties or potencies. For G1c and G1d, an additional distinction between these isoforms is the inclusion of an unknown domain encoded by exons 6 and 7 in the latter. As such, the higher Gld mRNA expression in fetal brain may indicate that the function of this domain is particularly related to developmental events.

\section{Netrin-G1 and Netrin-G2 mRNA Expression in Schizophrenia and Bipolar Disorder}

To date, only one other study has examined NTNG1 and NTNG2 mRNA expression in schizophrenia (Aoki-Suzuki et al, 2005), and found total NTNG1 and NTNG2 mRNA expression to be unchanged in orbitofrontal cortex and the superior temporal gyrus in a small Australian brain series (six controls $v s$ six schizophrenics). Both transcripts were also unaltered in the dorsolateral prefrontal cortex in schizophrenics from the SMRI array collection (AokiSuzuki et al, 2005); the authors did not report the bipolar disorder subjects in this cohort. Further examination of specific NTNG1 isoforms in the dorsolateral prefrontal cortex found that G1c and G1d were decreased in schizophrenia. Our finding of a trend decrease in G1c mRNA in the temporal lobe in schizophrenia (significant if the outlier is omitted) is consistent with Aoki-Suzuki et al (2005), but we did not replicate their finding of decreased G1d mRNA in schizophrenia. Furthermore, we report here that NTNG2 mRNA is decreased in the temporal cortex in schizophrenia and bipolar disorder, the expression of NTNG2 mRNA having been unchanged in the cortical regions examined by Aoki-Suzuki et al (2005).

These differences in results may be due to the fact that the two studies examined different brain regions; methodological differences may also contribute to the discrepancies. For example, our use of ISHH allowed us to detect changes in NTNG2 mRNA that were present in some, but not all subfields, effects that would have been diluted using $\mathrm{qPCR}$ on homogenized tissue. Furthermore, Aoki-Suzuki et al (2005) did not take into account the methodological variables discussed below, and did not include all subjects in each diagnostic group (in some instances, it appears that 
as many as 10 subjects were omitted due to amplification failure).

As in any study of this kind, many factors other than diagnosis per se may underlie our findings of disease-related changes in NTNG1 and NTNG2 expression. We attempted to control for several known confounders (eg RIN, age, $\mathrm{pH}$, post-mortem delay) using ANCOVA, and our results were robust to these factors. Factors to which patients and controls were differentially exposed in life, notably prescribed, recreational, and illicit drugs, are more difficult to control for. Neither smoking nor alcohol use had a significant effect upon NTNG1 or NTNG2 mRNA expression, while substance misuse was found to increase NTNG2 mRNA expression, making it unlikely that these factors account for reduced NTNG1 and NTNG2 mRNA expression in schizophrenia and bipolar disorder. Regarding antipsychotic medication, for NTNG1 mRNA isoforms, no correlations were detected with lifetime exposure, and antipsychotic drug treatment in rats did not alter hippocampal NTNG1 mRNA expression. Whether medication affects the NTNG2 mRNA results is less clear: NTNG2 mRNA was negatively correlated with lifetime antipsychotic exposure in schizophrenia, suggesting an effect; on the other hand, no correlation was seen in bipolar disorder subjects, and in rats, antipsychotics either did not affect (haloperidol) or increased (clozapine) NTNG2 mRNA. Moreover, NTNG2 mRNA reductions remain significant in bipolar disorder when the analyses are repeated with lifetime fluphenazine equivalents included as a covariate (data not shown). The negative correlation in the schizophrenic patients may in fact index illness severity. Comparable information for the major drug classes received by the bipolar disorder patients, notably mood stabilizers, and antidepressants, was not available, and so we cannot assess whether such medications might have confounded our findings.

\section{Netrin-G1 and Netrin-G2 and the Pathophysiology of Schizophrenia and Bipolar Disorder}

Most pathophysiological models of schizophrenia propose that the disorder is one of the synapse and of connectivity (Andreasen, 1999; Frankle et al, 2003; McGlashan and Hoffman, 2000; Mirnics et al, 2001; Moises et al, 2002; Stephan et al, 2006). Data indicative of altered synaptic density and/or function in the temporal lobe in schizophrenia has come from post-mortem studies of synaptic protein expression as well as ultrastructural findings (for reviews see Harrison and Eastwood, 2001; Honer et al, 2000; Honer and Young, 2004) and although there are fewer data in bipolar disorder, synaptic alterations also appear to be present (Eastwood and Harrison, 2000; Fatemi et al, 2001; Harrison, 2002; Knable et al, 2004; Torrey et al, 2005; Vawter et al, 2002). Our finding of decreased G1c and NTNG2 mRNAs provide further indications of altered synaptic protein gene expression in the temporal lobe in both disorders. Additionally, the roles of NTNG1 and NTNG2 in synapse formation and maintenance (Nakashiba et al, 2000, 2002; Yin et al, 2002) imply that the reductions may not only reflect, but be causally related to, the synaptic changes.

The cortical synaptic pathology of schizophrenia, and probably that of bipolar disorder, affects glutamatergic
(Eastwood and Harrison, 2000, 2005; Harrison and Eastwood, 1998; Sawada et al, 2005) as well as GABAergic (Heckers et al, 2002; Knable et al, 2004; Lewis et al, 2005) synapses. Our finding that NTNG1 and NTNG2 mRNAs are predominantly expressed by excitatory neurons suggests that their decreased expression in schizophrenia and bipolar disorder may particularly affect glutamatergic synapses, while the fact that NTNG1 mRNA is also expressed by some hippocampal interneurons suggests that it may also be relevant for the GABAergic changes noted in the disorder. However, the identity of the post-synaptic neuronal populations affected by the NTNG1 and NTNG2 alterations is unclear, since there is no information regarding the cellular distribution of NGL-1 and NGL-2 in human brain. Investigation of the expression of NGl-1 and NGL-2, using both ISHH and immunocytochemical approaches, will be required to clarify the post-synaptic partners in these neural circuits.

In the case of NTNG2, the suggestion that its decreased expression may primarily impact on glutamatergic synapses is supported by in vitro studies that have examined the effect of over- and under-expression of its ligand NGL-2, and the discovery that NGL-2 binds to the first two PDZ domains of PSD-95 (Kim et al, 2006). NGL-2-coated beads induce the aggregation of PSD-95 and associated proteins, including the NMDA receptor subunit NR2A, while siRNA knockdown of NGL-2 reduces the number of excitatory but not inhibitory synapses in cultured neurons (Kim et al, 2006). Furthermore, over-expression of NGL-2 increases the number of PSD-95 positive, but not negative, dendritic protrusions (Kim et al, 2006). These data, together with the importance of PSD-95 in glutamatergic synapse formation and receptor recruitment (Garner et al, 2000; Kim and Sheng, 2004), indicate that adhesion between NTNG2 and NGL-2 is required for maintenance of excitatory synapses and recruitment of NMDA receptors to the synapse. Thus, decreased NTNG2 mRNA in schizophrenia and bipolar disorder may contribute particularly to the NMDA receptor-mediated glutamatergic synaptic alterations observed in both disorders (Harrison et al, 2003; Law and Deakin, 2001; McCullumsmith et al, 2007; Scarr et al, 2003).

As NTNG1 and NTNG2 are expressed by different excitatory neuron populations (see Figures 2 and 3), their altered expression will affect different glutamatergic synapses. The widespread distribution of NTNG2 suggests that it may modulate excitatory synaptic circuits throughout the hippocampus and inferior temporal lobe, whereas the predominant localization of NTNG1 mRNA to layer 3 perirhinal and inferior temporal cortex pyramidal neurons (Figures 2a and 3c) implicates corticocortical connections. As functional differences between the alternatively spliced NTNG1 isoforms have yet to be examined, no comment can be made as to the significance of the fact that G1c, but not the other NTNG1 isoforms was decreased in schizophrenia and bipolar disorder.

\section{Schizophrenia Associated Netrin-G1 and Netrin-G2 SNPs are not Associated with mRNA Expression}

SNPs in the genes for NTNG1 and NTNG2 reported to be associated with schizophrenia are either intronic and/or within untranslated regions, suggesting that any disease 
susceptibility they may confer occurs by altering some facet of the expression of the genes. Our data showing that NTNG1 or NTNG2 mRNA expression is not associated with schizophrenia-associated SNPs suggest that altered mRNA expression is not the mechanism by which genetic variation of NTNG1 and NTNG2 confers disease susceptibility, although the low minor allele frequency of the NTNG2 SNP examined (rs1105684: $\sim 16 \%$ in our study) means we may have been underpowered to detect small effects of this kind.

Finally, although our interest in NTNG1 and NTNG2 was primarily with regard to schizophrenia, we found more significant changes in their expression in bipolar disorder. Possible linkage has been noted for the NTNG2 locus (9q34) with early onset bipolar disorder (Faraone et al, 2006) and with affective disorder (Venken et al, 2005), and for the NTNG1 locus (1p13.3) with psychosis and bipolar disorder (Cheng et al, 2006). It will therefore be of interest to determine whether the genes for NTNG1 and NTNG2 are associated with bipolar disorder.

\section{ACKNOWLEDGEMENTS}

This study was supported by the UK Medical Research Council and the Stanley Medical Research Institute. We thank Jamie Anderson, Greg Bristow, and Mary Walker for technical assistance, and Dr Phil Burnet for provision of animal tissue. Post-mortem tissue was provided by the Stanley Medical Research Institute courtesy of Drs Michael B Knable, E Fuller Torrey, Maree J Webster, Serge Weis, and Robert $\mathrm{H}$ Yolken. This research would not have been possible without the participation of patients with schizophrenia and bipolar disorder, their families and control subjects and we are grateful for their generosity.

\section{DISCLOSURE/CONFLICTS OF INTEREST}

Dr Eastwood: My research is funded by the UK Medical Research Council and NARSAD. I declare that, except for income received from my primary employer, no financial support or compensation has been received from any individual or corporate entity over the past 3 years for research or professional service and that there are no personal financial holdings that could be perceived as constituting a potential conflict of interest.

Professor Harrison: My group's research is supported by the UK Medical Research Council, Stanley Medical Research Institute, NARSAD, Wellcome Trust, and an unrestricted educational grant from GlaxoSmithKline. In the past 3 years, I have received honoraria for giving educational lectures or chairing scientific meetings from Bristol Myers Squibb, GlaxoSmithKline, Janssen, Lilly, Merck, Sanofi, and Servier pharmaceutical companies, and I have been a scientific advisor to Curidium, Janssen, and Wyeth. There are no personal financial holdings that could be perceived as constituting a potential conflict of interest.

\section{REFERENCES}

Andreasen NC (1999). A unitary model of schizophrenia: Bleuler's 'fragmented phrene' as schizencephaly. Arch Gen Psychiatry 56: 781-787.
Aoki-Suzuki M, Yamada K, Meerabux J, Iwayama-Shigeno Y, Ohba $\mathrm{H}$, Iwamoto $\mathrm{K}$ et al (2005). A family-based association study and gene expression analyses of netrin-G1 and -G2 genes in schizophrenia. Biol Psychiatry 57: 382-393.

Arnold SE (2000). Cellular and molecular neuropathology of the parahippocampal region in schizophrenia. Ann NY Acad Sci 911: 275-292.

Barton AJL, Najlerahim A, Pearson RCA, Harrison PJ (1993). Preand postmortem influences on brain RNA. J Neurochem 61: $1-11$.

Biederer T (2006). Hooking up new synapses. Nat Neurosci 9: 1203-1204.

Cheng R, Juo SH, Loth JE, Nee J, Iossifov I, Blumenthal R et al (2006). Genome-wide linkage scan in a large bipolar disorder sample from the National Institute of Mental Health genetics initiative suggests putative loci for bipolar disorder, psychosis, suicide, and panic disorder. Mol Psychiatry 11: 252-260.

Chih B, Engelman H, Scheiffele P (2005). Control of excitatory and inhibitory synapse formation by neuroligins. Science 307 : 1324-1328.

Clancy B, Darlington RB, Finlay BL (2001). Translating developmental time across mammalian species. Neuroscience 105 7-17.

Dean C, Dresbach T (2006). Neuroligins and neurexins: linking cell adhesion, synapse formation and cognitive function. Trends Neurosci 29: 21-29.

Duvernoy HM (1998). The Human Hippocampus. Functional Anatomy, Vascularization and Serial Sections with MRI, 2nd edn. Springer: Berlin.

Eastwood SL, Burnet PW, Harrison PJ (2000). Expression of complexin I and II mRNAs and their regulation by antipsychotic drugs in the rat forebrain. Synapse 36: 167-177.

Eastwood SL, Cotter D, Harrison PJ (2001). Cerebellar synaptic protein expression in schizophrenia. Neuroscience 105: 219-229.

Eastwood SL, Harrison PJ (2000). Hippocampal synaptic pathology in schizophrenia, bipolar disorder and major depression: a study of complexin mRNAs. Mol Psychiatry 5: 425-432.

Eastwood SL, Harrison PJ (2005). Decreased expression of vesicular glutamate transporter 1 and complexin II mRNAs in schizophrenia: further evidence for a synaptic pathology affecting glutamate neurons. Schizophr Res 73: 159-172.

Eastwood SL, Salih T, Harrison PJ (2005). Differential expression of calcineurin A subunit mRNA isoforms during rat hippocampal and cerebellar development. Eur J Neurosci 22: 3017-3024.

Faraone SV, Lasky-Su J, Glatt SJ, Van EP, Tsuang MT (2006). Early onset bipolar disorder: possible linkage to chromosome $9 \mathrm{q} 34$. Bipolar Disord 8: 144-151.

Fatemi SH, Earle JA, Stary JM, Lee S, Sedgewick J (2001). Altered levels of the synaptosomal associated protein SNAP-25 in hipoocampus of subjects with mood disorders and schizophrenia. Neuroreport 12: 3257-3262.

Frankle WG, Lerma J, Laruelle M (2003). The synaptic hypothesis of schizophrenia. Neuron 39: 205-216.

Fukasawa M, Aoki M, Yamada K, Iwayama-Shigeno Y, Takao H, Meerabux J et al (2004). Case-control association study of human netrin G1 gene in Japanese schizophrenia. J Med Dent Sci 51: 121-128.

Garner CC, Nash J, Huganir RL (2000). PDZ domains in synapse assembly and signalling. Trends Cell Biol 10: 274-280.

Harrison PJ (1999). The neuropathology of schizophrenia. A critical review of the data and their interpretation. Brain 122: 593-624.

Harrison PJ (2002). The neuropathology of primary mood disorder. Brain 125: 1428-1449.

Harrison PJ (2004). The hippocampus in schizophrenia: a review of the neuropathological evidence and its pathophysiological implications. Psychopharmacology 174: 151-162. 
Harrison PJ, Eastwood SL (1998). Preferential involvement of excitatory neurons in the medial temporal lobe in schizophrenia. Lancet 352: 1669-1673.

Harrison PJ, Eastwood SL (2001). Neuropathological studies of synaptic connectivity in the hippocampal formation in schizophrenia. Hippocampus 11: 508-519.

Harrison PJ, Heath PR, Eastwood SL, Burnet PWJ, McDonald B, Pearson RCA (1995). The relative importance of premortem acidosis and postmortem interval for human brain gene expression studies: selective mRNA vulnerability and comparison with their encoded proteins. Neurosci Lett 200: 151-154.

Harrison PJ, Law AJ, Eastwood SL (2003). Glutamate receptors and transporters in the hippocampus in schizophrenia. Ann NY Acad Sci 1003: 94-101.

Harrison PJ, Owen MJ (2003). Genes for schizophrenia? Recent findings and their pathophysiological implications. Lancet 361: 417-419.

Harrison PJ, Weinberger DR (2005). Schizophrenia genes, gene expression, and neuropathology: on the matter of their convergence. Mol Psychiatry 10: 40-68.

Heckers S, Stone D, Walsh J, Shick J, Koul P, Benes F (2002). Differential hippocampal expression of glutamic acid decarboxylase 65 and 67 messenger RNA in bipolar disorder and schizophrenia. Arch Gen Psychiatry 59: 521-529.

Honer WG, Young CE (2004). Presynaptic proteins and schizophrenia. Int Rev Neurobiol 59: 1751-1799.

Honer WG, Young C, Falkai P (2000). Synaptic pathology. In: Harrison PJ, Roberts GW (eds). The Neuropathology of Schizophrenia. Progress and Interpretation. Oxford University Press: Oxford. pp 105-136.

Imbeaud S, Graudens E, Boulanger V, Barlet X, Zaborski P, Eveno $\mathrm{E}$ et al (2005). Towards standardization of RNA quality assessment using user-independent classifiers of microcapillary electrophoresis traces. Nucleic Acids Res 33: e56.

Insausti R, Amaral D (2004). Hippocampal formation. In: Paxinos G, Mai G (eds). The Human Nervous System, 2nd edn. Academic: San Diego. pp 871-914.

Kim E, Sheng M (2004). PDZ domain proteins of synapses. Nat Rev Neurosci 5: 771-781.

Kim S, Burette A, Chung HS, Kwon SK, Woo J, Lee HW.et al (2006). NGL family PSD-95-interacting adhesion molecules regulate excitatory synapse formation. Nat Neurosci 9: 1294-1301.

Knable MB, Barci BM, Webster MJ, Meador-Woodruff J, Torrey EF, Stanley Neuropathology Consortium (2004). Molecular abnormalities of the hippocampus in severe psychiatric illness: postmortem findings from the Stanley Neuropathology Consortium. Mol Psychiatry 9: 609-620.

Law AJ, Deakin JF (2001). Asymmetrical reductions of hippocampal NMDAR1 glutamate receptor mRNA in psychoses. Neuroreport 12: 2971-2974.

Law AJ, Hutchinson LJ, Burnet PWJ, Harrison PJ (2004). Antipsychotics increase microtubule-associated protein 2 mRNA but not spinophilin mRNA in rat hippocampus and cortex. J Neurosci Res 76: 376-382.

Lewis DA, Levitt P (2002). Schizophrenia as a disorder of neurodevelopment. Annu Rev Neurosci 25: 409-432.

Lewis DA, Hashimoto T, Volk DW (2005). Cortical inhibitory neurons and schizophrenia. Nat Rev Neurosci 6: 312-324.

Lin JC, Ho WH, Gurney A, Rosenthal A (2003). The netrin-G1 ligand NGL-1 promotes the outgrowth of thalamocortical axons. Nat Neurosci 6: 1270-1276.

Lipska BK, Deep-Soboslay A, Weickert CS, Hyde TM, Martin CE, Herman MM et al (2006). Critical factors in gene expression in postmortem human brain: focus in studies in schizophrenia. Biol Psychiatry 60: 650-658.
Lise MF, El-Husseini A (2006). The neuroligin and neurexin families: from structure to function at the synapse. Cell Mol Life Sci 63: 1833-1849.

Nakashiba T, Ikeda T, Nishimura S, Tashiro K, Honjo T, Culotti JG et al (2000). Netrin-G1: a novel glycosyl phosphatidylinositollinked mammalian netrin that is functionally divergent from classical netrins. J Neurosci 20: 6540-6550.

Nakashiba T, Nishimura S, Ikeda T, Itohara S (2002). Complementary expression and neurite outgrowth activity of netrin-G subfamily members. Mech Dev 111: 47-60.

Marenco S, Weinberger DR (2000). The neurodevelopmental hypothesis of schizophrenia: following a trail from the cradle to the grave. Dev Psychopathol 12: 501-527.

McCullumsmith RE, Kristiansen LV, Beneyto M, Scarr E, Dean B, Meador-Woodruff JH (2007). Decreased NR1, NR2A, and SAP102 transcript expression in the hippocampus in bipolar disorder. Brain Res 1127: 108-118.

McGlashan TH, Hoffman RE (2000). Schizophrenia as a disorder of developmentally reduced synaptic connectivity. Arch Gen Psychiatry 57: 637-648.

Meerabux JM, Ohba H, Fukasawa M, Suto Y, Aoki-Suzuki M, Nakashiba $\mathrm{T}$ et al (2005). Human netrin-G1 isoforms show evidence of differential expression. Genomics 86: 112-116.

Mirnics K, Middleton FA, Lewis DA, Levitt P (2001). Analysis of complex brain disorders with gene expression microarrays: schizophrenia as a disease of the synapse. Trends Neurosci 24: 479-486.

Mitsui K, Nakajima D, Ohara O, Nakayama M (2002). Mammalian fat3: a large protein that contains multiple cadherin and EGFlike motifs. Biochem Biophys Res Commun 290: 1260-1266.

Miyashita T, Nishimura-Akiyoshi S, Itohara S, Rockland KS (2005). Strong expression of NETRIN-G2 in the monkey claustrum. Neuroscience 136: 487-496.

Moises HW, Zoega T, Gottesman II (2002). The glial growth factors deficiency and synaptic destabilization hypothesis of schizophrenia. BMC Psychiatry 2: 8.

Sawada K, Barr AM, Nakamura M, Arima K, Young CE, Dwork AJ et al (2005). Hippocampal complexin proteins and cognitive dysfunction in schizophrenia. Arch Gen Psychiatry 62: 263-272.

Scarr E, Pavey G, Sundram S, MacKinnon A, Dean B (2003). Decreased hippocampal NMDA, but not kainate or AMPA receptors in bipolar disorder. Bipolar Disord 5: 257-264.

Stan AD, Ghose S, Gao X-M, Roberts RC, Lewis-Amezcua K, Hatanpaa KJ et al (2006). Human post-mortem tissue: what quality markers matter? Brain Res 1123: 1-11.

Stephan KE, Baldeweg T, Friston KJ (2006). Synaptic plasticity and dysconnection in schizophrenia. Biol Psychiatry 59: 929-939.

Torrey EF, Barci BM, Webster MJ, Bartko JJ, Meador-Woodruff JH, Knable MB (2005). Neurochemical markers for schizophrenia, bipolar disorder, and major depression in postmortem brains. Biol Psychiatry 57: 252-260.

Varoqueaux F, Aramuni G, Rawson RL, Mohrmann R, Missler M, Gottmann $\mathrm{K}$ et al (2006). Neuroligins determine synapse maturation and function. Neuron 51: 741-754.

Vawter MP, Freed WJ, Kleinman JE (2000). Neuropathology of bipolar disorder. Biol Psychiatry 48: 486-504.

Vawter MP, Thatcher L, Usen N, Hyde TM, Kleinman JE, Freed WJ (2002). Reduction of synapsin in the hippocampus of patients with bipolar disorder and schizophrenia. Mol Psychiatry 7: 571-578.

Venken T, Claes S, Sluijs S, Paterson AD, Van DC, Adolfsson R et al (2005). Genomewide scan for affective disorder susceptibility Loci in families of a northern Swedish isolated population. Am J Hum Genet 76: 237-248.

Yin Y, Miner JH, Sanes JR (2002). Laminets: laminin- and netrinrelated genes expressed in distinct neuronal subsets. Mol Cell Neurosci 19: 344-358. 